\title{
Research Paper: Psychometric Properties of the Eating Beliefs Questionnaire (EBQ-18) in A Nonclinical Iranian Sample: A Transdiagnostic Measure
}

\author{
Hanieh Alasty $^{1}$ (D), Jafar Hasani ${ }^{* *}$ (D), Mehdi Akbari ${ }^{1}$ (D) , Shahram Mohammadkhani' ${ }^{1}$ (D)
}

1. Department of Clinical Psychology, Kharazmi University, Tehran, Iran.

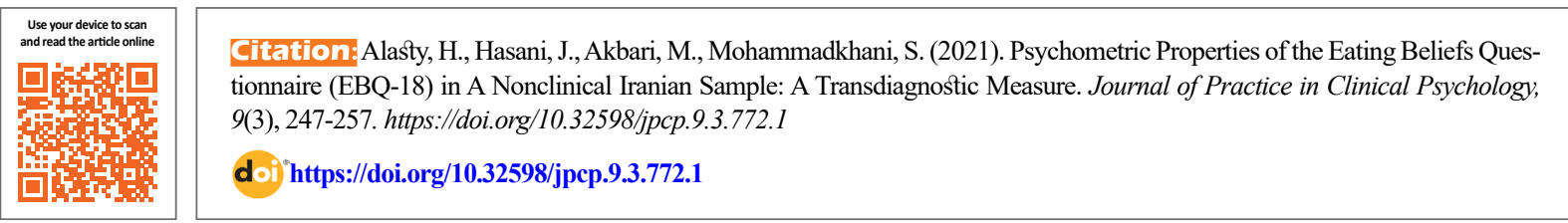

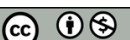

Article info:

Received: 23 Apr 2021

Accepted: 02 Jun 2021

Available Online: $01 \mathrm{Jul} 2021$
Keywords:

Bulimia, Binge eating, Eating disorder, Eating Beliefs

Questionnaire (EBQ-18),

Psychometric, A Transdiagnostic

Measure

\section{ABSTRACT}

Objective: Binge eating is a transdiagnostic construct and one of the main components of eating and emotional disorders. Meta-cognitive beliefs about eating play an important role in the maintenance of binge eating. The Eating Beliefs Questionnaire (EBQ-18) is a self-report questionnaire, which measures negative, positive, and permissive beliefs about binge eating. This cross-sectional study aims to assess the psychometric properties of the EBQ-18 in a community sample.

Methods: A total of 501 participants ( $413=$ females, $88=$ males) were selected through multistage cluster sampling and were administered the EBQ-18, the Binge Eating Scale (BES), the Dutch Eating Behavior Questionnaire (DEBQ), the Body Image Concern Inventory (BICI), the Acceptance and Action Questionnaire (AAQ-II), and the Intolerance of Uncertainty Scale (UIS). Construct validity, internal consistency, convergent and divergent validity of the EBQ18 were determined using Exploratory Factor Analysis, Confirmatory Factor Analysis.

Results: The EBQ-18 possesses a three-factor structure and a high internal consistency $(\alpha=.91)$. The EBQ-18 showed convergent validity with the BES and the DEBQ, divergent validity with the BICI, AAQ-II, and The UIS.

Conclusion: The goodness-of-fit indices were acceptable and the data showed adequate fit to the three-factor model. In conclusion, findings provide initial support for the validity and reliability of the EBQ-18.

\footnotetext{
* Corresponding Author:

Jafar Hasani, PhD.

Address: Department of Clinical Psychology, Kharazmi University, Tehran, Iran.

Tel: +98 (912) 7365172

E-mail: hasanimehr57@yahoo.com
} 


\section{Highlights}

- EBQ-18-Persian version has good internal consistency in terms of Cronbach's Alpha;

- Persian version of the EBQ-18 indicated the convergent validity;

- Confirmatory Factor Analysis yielded to the three-factor model;

- Persian version of the EBQ-18 revealed a good fit to the empirical data.

\section{Plain Language Summary}

Considering that binge eating is a transdiagnostic structure and includes cognitive, emotional and behavioral dimensions of the individual and the resulting physical and psychological problems lead to increase economic, clinical and social costs. creating a transdiagnostic model is necessary in order to reduce the symptoms of binge eating, so in this study, the psychometric properties (validity and reliability) of the Persian version of the short form of the Eating Beliefs Questionnaire (18-item version) were investigated in a non-clinical population. In conclusion, results of the present study demonstrate that the EBQ-18 possesses proper psychometric properties in a non-clinical Iranian sample. Moreover, since this instrument measures one of the transdiagnostic constructs in the realm of eating and emotional disorders, it can be used as a sensitive index for the assessment of the effectiveness of transdiagnostic approaches in clinical trial studies. It is also very useful for preventing other mental disorders and reducing economic and social cost.

\section{Introduction}

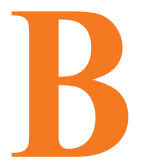

inge eating is one of the main underlying components of different types of eating disorders and emotional problems (American Psychiatric Association. Diagnostic and Statistical Manual of Mental Disorders [DSM-5]); American Psychiatric Association (APA)., 2013). In a binge eating episode, the individual is overwhelmed by a sense of loss of control over the act of eating and consumes an objectively large amount of food in a discrete period (less than two hours) when one is not hungry. This action is later accompanied by feelings of guilt and disgust (DSM-5; American Psychiatric Association (APA)., 2013). Previous studies report that the prevalence of binge eating disorders ranges from $1 \%$ to $3 \%$ in the general population, and it is more prevalent in females (McCuen-Wurst, Ruggieri, \& Allison, 2018).

Few studies have focused on the prevalence of binge eating in Iran. Nobakht and Dejkam (2000) reported the prevalence of binge eating as $6.6 \%$ in female adolescents in Tehran (Nobakht \& Dezhkam, 2000; Rezaei M, Aflakseir A, Yavari A, Mohamadi N, 2015). Moreover, nearly $80 \%$ of the people diagnosed with binge eating disorder also suffer from other psychiatric disorders (McCuenWurst et al., 2018). Besides, binge eating increases the risk for physical problems (McCuen-Wurst et al., 2018; Marzilli, Cerniglia, \& Cimino, 2018). Indeed, binge eat- ing is one of the common components of different types of eating disorders (anorexia nervosa, bulimia nervosa, and binge eating disorder) in addition to other affective disorders such as anxiety and depression (Burton et al., 2018). Because binge eating is a transdiagnostic construct that includes cognitive, emotional, and behavioral dimensions, the physical or psychological problems of this disorder would lead to increasing economic, social, and clinical costs (Marzilli et al., 2018). Thus, providing a valid tool for evaluating and diagnosing binge eating symptoms is necessary (Burton et al., 2018).

Most of the available tools which measure binge eating do not consider metacognitive components of this disorder in detail and distinctively (Nattiv et al., 2007; HERZOG et al., 1993). Also, the process and the cognitive stages of binge eating have not been investigated (Marzilli et al., 2018; Goldschmidt, Wall, Loth, Bucchianeri, \& Neumark-Sztainer, 2014; Stice, Marti, \& Rohde, 2013; Tanofsky-Kraff et al., 2011). Applying other psychometric instruments, namely the Eating Disorder Examination Questionnaire (EDE-Q) or the structured clinical interview for DSM, is costly and difficult to access (Burton, Abbott, Modini, \& Touyz, 2016). Therefore, it is essential to provide a useful and user-friendly instrument for assessing and diagnosing binge eating symptoms (Burton et al., 2016). Fairburn and Harison (2003) introduced a therapy model for eating disorders based on the principles of the transdiagnostic approach (Fairburn \& Harrison, 
2003; Fairburn et al., 2013). However, none of the cited research addressed metacognitive beliefs about eating behavior objectively and clearly (Cooper \& Grave, 2017).

The Eating Beliefs Questionnaire (EBQ-18) is one of the most useful instruments for assessing binge eating. This questionnaire was developed by Burton et al. in 2015 based on the metacognition theory of Fairburn et al. (Fairburn \& Harrison, 2003; Burton et al., 2015). At first, the EBQ had 32 items, and results of the Confirmatory Factor Analysis (CFA) in the general and clinical populations supported the 3-factor structure. Considering the increasingly important role of binge eating behavior in psychopathology, evaluation of the efficacy of transdiagnostic therapies, the mediating role of emotional disorders, and the ease of implementation, the 18-item short form of the EBQ was invented, which assesses positive, negative, and permissive beliefs in relation to food and eating (Burton et al., 2018). According to the metacognition theory and the cognitive model of bulimia, negative beliefs refer to a perception of having no control over binge eating or food intake, for instance, "I cannot control my urges to eat". Positive beliefs relate to the perceived benefits of binge eating, for instance, "Eating helps me to cope with negative feelings", and finally permissive beliefs might relate to allowing oneself to binge or continue to binge, for example, "It won't make a difference if I eat more” (Burton et al., 2018).

The psychometric properties of this measure were assessed. Similar to the 32-item version, the EBQ-18 was found to be a valid and reliable measure with excellent internal consistency $(\alpha=0.96)$ and good test-retest reliability ( $\mathrm{r}=0.75$ ) (Burton et al., 2018; Burton et al., 2016) anorexia nervosa (binge/purge subtype. Besides, this measure shows adequacy regarding the assessment of binge eating pathology in general and clinical samples. Thus, it can be used as a useful tool to assess the effectiveness of obesity treatments and bariatric surgeries (Burton et al., 2018). Over the last decades, it was assumed that mere behavioral interventions and weight control reduce eating disorder symptoms. Still, evidence suggests that behavioral approaches cannot prevent the onset of eating disorders or produce a sustainable treatment (Pennesi \& Wade, 2016). Because of the ego-syntonic nature of these disorders and practical avoidance in patients with binge eating disorders, direct correction, and change of beliefs related to eating behavior are impossible. Furthermore, individuals with binge eating disorders are resistant to treatment and alteration of negative metacognitive beliefs concerning eating, body shape, and weight (Cockell, Geller, \& Linden, 2003). Thus, a transdiagnostic measure is needed to assess beliefs about eating. This knowledge enriches therapies to be more beneficial to a wider variety of people. In recent years, research interest has been raised in the area of transdiagnostic approaches in Iran. However, the lack of a short-form of a valid measure to research in psychopathology and effectiveness of treatments has been a limitation (Akbari \& Khanipour, 2018) metacognitive model, model of emotional schemas and acceptance-based model. Participants were 557 students whom were studied at University of Tehran in Iran. Data were gathered by Penn State Worry Questionnaire (PSWQ; Akbari et al., 2015).

The current study has addressed this limitation by providing a short form of a valid transdiagnostic measure: the EBQ-18. Consequently, it is hoped that the findings of this study would be beneficial. The main aim of the present study is to assess the psychometric properties (validity and reliability) of the Persian version of the Eating Beliefs Questionnaire short-form (EBQ-18) in a nonclinical sample.

\section{Materials and Methods}

\section{Study participants}

The statistical population of the present study includes all Iranian men and women (18 to 45 years old) who were fluent in Persian and could read and write Persian. Also, they should be present in cyberspace and Instagram and WhatsApp applications in the years 2017-2019. At first, the researcher takes the available sampling method in the Instagram application space. After the initial sampling, the inclusion criteria were having 18 to 45 years old, being fluent in Persian literacy. The exclusion criterion was not being pregnant.

As presented in Table 1, the sample consists of 88 males (17.6\%) and 413 females (82.6\%). The participants' age ranged from 18 to 45 years. The Mean \pm SD age of the male samples was $29.75 \pm 7.36$ years, and of females, $31.98 \pm 7.26$ years. Among the female participants, 79 $(19 \%)$ had a diploma and an undergraduate degree, 147 (36\%) had a bachelor's degree, $143(35 \%)$ had a master's degree, and 44 (11\%) had a PhD degree. Also, 195 (47\%) were single, and 218 (53\%) were married. Among men, $19(22 \%)$ had a diploma and an undergraduate degree, 30 (34\%) had a bachelor's degree, 32(36\%) had a master's degree, and 7 (8\%) had a PhD degree. Finally, $33(37 \%)$ were single, and $55(63 \%)$ were married. 


\section{Study procedure}

At first, with the developers' permission of the original version of the EBQ-18, the items were translated into Persian by two bilingual Psychology experts independently. Next, the equivalence of the two versions was checked and confirmed; as a result, the content validity was satisfactory. As an initial assessment, the EBQ-18 was administered to a sample of 30 participants. Experts in the transdiagnostic approach further analyzed the content and fluency of the items. According to their evaluation, none of the items were altered.

A literature review shows no precise strategy for determining the sample size using structural equation modeling, but Klein has proposed another solution for determining the sample size (Kline, 2015). To determine the sample size for exploratory factor analysis, for each item of a questionnaire (18 items), between 10 to 20 subjects are needed. Also, for confirmatory factor analysis, 20 subjects are added to each sample (three factors). As a result, the minimum sample required in this study is 420 subjects, which eventually reached 501 subjects. In this study, all data were virtually collected. The subjects received the consent link in Google Doc software through the researcher's Instagram page. After giving their informed consent, they completed the questionnaires entered in Google Doc.

The convergent and divergent validities of the EBQ-18 were examined using the Pearson correlation coefficient with other questionnaires: the Binge Eating Scale (BES), The Dutch Eating Behavior Questionnaire (DEBQ), the Body Image Concern Inventory (BICI), the Acceptance and Action Questionnaire (AAQ-II), and the Intolerance of Uncertainty Scale (IUS). The construct validity and the reliability of the EBQ-18 were evaluated using Expletory Factor Analysis (EFA) and the internal consistency (the Cronbach $\alpha$ ), respectively.

\section{Study measures}

The Eating Beliefs Questionnaire (EBQ-18)

This 18-item self-report measure was developed by Burton et al. (2018). It measures positive (6 items), negative ( 6 items), and permissive beliefs ( 6 items) about food and eating behavior. The items are scored on a 5-point Likert from 1 (strongly disagree) to 5 (strongly agree). The Cronbach $\alpha$ coefficient and 2-week test-retest reliability were reported $(\alpha=0.96)$ and $(r=0.75)$, respectively (Burton et al., 2018).

\section{Binge Eating Scale (BES)}

BES was developed by Gormally, Black, Daston, \& Rardin, in 1982 to assess the severity of binge eating in individuals with obesity. It has 16 items, and each consists of three to four sentences. The participants are requested to choose the item that best describes them (Gormally et ai., 1982). The psychometric properties of the Persian version of the BES have been examined in Iran. The reliability of this measure was reported using testrest coefficient $(\mathrm{r}=0.72)$, split-half coefficient $(\mathrm{r}=0.67)$, and the Cronbach $\alpha$ method $(\alpha=0.85)$. Sensitivity, specificity, and the cut-off point of the Persian version of the BES were reported $84.6,80.8$, and 17 , respectively (Moloodi, Dezhkam, Moutabi, \& Omidvar, 2010).

\section{Dutch Eating Behavior Questionnaire (DEBQ)}

DEBQ was developed by Frijters et al. in 1986 to assess eating attitudes. It has 33 items and is scored on a 5-point Likert. It consists of 5 subscales that measure emotional (13 items), external (10 items), and restrained eating (10 items) (van Strien, Frijters, Bergers, \& Defares, 1986). It has demonstrated proper validity and reliability. Several studies have reported its Cronbach $\alpha$ coefficient to be larger than 0.82 (Jahnke \& Warschburger, 2008). Psychometric properties of the DEBQ have been examined in Iran (Salehi Fadarid, Madaah Shoorcheh, \& Nemati, 2011).

\section{Body Image Concern Inventory (BICI)}

Littleton et al. introduced this inventory in 2005. BICI consists of 19 items that measures dissatisfaction and concern about appearance. The participants are asked to score each item, based on the degree that it represents their emotions or behavior, on a 5-point Likert from $1=$ "I never have this feeling/do this" to 5= "I always have this feeling/do this". The total score ranges from 19 to 95, with higher scores indicating more dissatisfaction and concern about the body image. Previous research has reported that the BICI is a valid and reliable tool (Littleton, Axsom, \& Pury, 2005). This measure has demonstrated proper internal consistency $(\alpha=0.93)$. The correlation of the items with the total score ranged from 0.32 to 0.73 , and it was 0.62 for the mean score (Littleton et al., 2005). The internal consistency of the BICI was reported as 0.89 in Iran (Alavizadeh SM, 2011).

\section{Acceptance and Action Questionnaire (AAQ-II)}

AAQ-II was developed by Bond et al. in 2011 and is a 10 -item version of the AAQ-I which Hayes designed in 2000 (Bond et al., 2011; Hayes et al., 2004). It is scored 
Table 1. Demographic information of the study samples

\begin{tabular}{|c|c|c|c|c|}
\hline \multirow{2}{*}{ Samples } & \multirow{2}{*}{ No.(\%) } & \multirow{2}{*}{ Age (y), Mean $\pm S D$} & \multicolumn{2}{|c|}{ No. (\%) } \\
\hline & & & Education & Marital Status \\
\hline \multirow{4}{*}{ Females } & \multirow{4}{*}{$413(82.4)$} & \multirow{4}{*}{$31.98 \pm 7.26$} & PhD: 44(11) & \\
\hline & & & MSc: 143(35) & Married: 218(53) \\
\hline & & & BSc: 147(36) & Single: 195(47) \\
\hline & & & Lower: 79(19) & \\
\hline \multirow{4}{*}{ Males } & \multirow{4}{*}{$88(17.16)$} & \multirow{4}{*}{$29.75 \pm 7.36$} & PhD: 7(8) & \\
\hline & & & MSc: 32(36) & Married: 55(63) \\
\hline & & & BSc: 30(34) & Single: $33(37)$ \\
\hline & & & Lower: 19(22) & \\
\hline \multirow{4}{*}{ Total } & \multirow{4}{*}{$501(100)$} & \multirow{4}{*}{$31.59 \pm 7.32$} & PhD: 51(10) & \\
\hline & & & MS.: 175(35) & Married: $273(54)$ \\
\hline & & & BSc: 177(35) & Single: 228(46) \\
\hline & & & Lower: 98(20) & \\
\hline
\end{tabular}

on a 7-point Likert form $1=$ "It is not true about me at all" to 7= "It is always true about me". Bond et al. (2011) studied 2816 participants across six samples, and their results indicated satisfactory reliability, structure, and discriminant validity of this measure. The mean score of the Cronbach $\alpha$ coefficient was reported 0.84 (ranged from 0.78 to 0.88 ). Test-retest reliability values were obtained as 0.81 and 0.79 in a 3 to 12 months interval, respectively (Bond et al., 2011). Satisfactory internal consistency and split-half coefficient (0.71 to 0.89$)$ have been reported for this measure in Iran. The Cronbach $\alpha$ coefficient was 0.81 in the present study (Abasi, Fatam, Moluodi,\& Zarabi, 2013).

\section{Intolerance of Uncertainty Scale (IUS)}

IUS was designed by Buhr, \& Dugas, in 2002 to assess the ability to tolerate uncertain situations and events. It includes 27 items and is rated on a 5-point Likert. Buhr and Dugas (2002) reported excellent Cronbach $\alpha$ coefficient $(\alpha=0.94)$ and good test-retest reliability over five weeks ( $r=0.74)$ (Buhr \& Dugas, 2002) for this measure. Akbari (2017) reported the Cronbach $\alpha$ of 0.88 and testretest reliability of 0.76 in a 3 -week interval. To assess the predictive validity of the IUS, its correlation with the Penn-State worry questionnaire $(\mathrm{r}=0.78)$ and the cognitive avoidance questionnaire $(\mathrm{r}=0.71)$ have been calculated (Akbari, 2017).

\section{Data analysis}

Data analysis was performed using SPSS-25 and LISREL 8.80 (SPSS, Chicago, IL; LISREL, Lincolnwood, IL). Exploratory factor analysis (principal component analysis method) was conducted to identify the underlying factors. Also, the reliability and internal consistencies of the EBQ-18 were estimated using the Cronbach $\alpha$ coefficient. To examine the association between the EBQ-18 and other related variables, convergent and divergent validities were used. To test the validity further, Confirmatory Factor Analysis (CFA) was performed.

\section{Results}

\section{Internal consistency (reliability)}

In the overall sample, the internal consistency was high for the positive beliefs scale $(\alpha=0.94)$ and the negative beliefs scale $(\alpha=0.88)$. The permissive beliefs scale demonstrated adequate internal consistency $(\alpha=0.76)$. The Cronbach $\alpha$ of the entire measure was 0.91 that indicates high internal consistency. Table 2 presents the internal consistency of the total score and the subscales of the EBQ-18 for males and females separately.

\section{Convergent and divergent validities}

Following the assessment of the reliability, convergent and divergent validity of the EBQ-18 were examined by evaluating its correlation with the scores of the DEBQ, 
Table 2. Internal consistency (reliability)

\begin{tabular}{ccccc}
\hline Samples & EBQ Total Score & Negative Beliefs & Positive Beliefs & Permissive Beliefs \\
\hline Females $(n=413)$ & 0.88 & 0.85 & 0.92 & 0.75 \\
Males $(n=88)$ & 0.91 & 0.87 & 0.93 & 0.76 \\
Total & 0.90 & 0.87 & 0.75 \\
\hline EBQ: Eating Beliefs Questionnaire & & & PRACTICE In \\
\hline
\end{tabular}

BES, AAQ-II, IUS, and BICI. To estimate the convergent validity, correlation coefficients of the EBQ-18 with the DEBQ and BES were calculated. The correlation coefficients of the EBQ-18 scores with the AAQ-II, IUS, and BICI were examined to evaluate the divergent validity. Table 3 presents the results of the convergent and divergent validities. As observed in this Table, The EBQ-18 showed high convergent validity with BES $(\mathrm{r}=0.63)$ and DEBQ $(\mathrm{r}=0.62)$. The EBQ-18 also demonstrated moderate divergent validity with BICI $(\mathrm{r}=0.40)$, IUS $(\mathrm{r}=0.27)$, and AAQ-II $(\mathrm{r}=0.28)$.

\section{Construct validity}

To examine the factor structure of the EBQ-18, Eexpletory Factor Analysis (EFA) was conducted to identify the underlying factors of the EBQ-18. As a prerequisite of the EFA and to determine the adequacy of the sample, Kaiser's measure of sampling adequacy was used. Kaiser's measure was 0.92 , indicating the adequacy of the sample to conduct the EFA. Moreover, to examine the power of the data to extract a specific factor structure, Bartlett's test of sphericity was used, and the results were significant.
First, EFA was conducted on the EBQ-18 items using the principal component extraction method and varimax rotation under the condition of eigenvalues equal to or greater than 1.0 and factor-loadings equal to or greater than 0.40 . Results revealed a 3 -factor solution accounted for $64.98 \%$ of the variance of the measure. According to Costello and Osborne (2005), items with factor loadings lower than 0.40 and items that load on more than two factors with the factor-loadings greater than 0.40 would be omitted from the analysis.

Since item 12 loaded on more than one factor, it was omitted from the final analysis. The eigenvalues were $7.75,2.13$, and 1.81 for each factor, respectively (Negative Beliefs Scale, Positive Beliefs Scale, Permissive Beliefs Scale). Moreover, the variance obtained for each factor was 27.23, 21.60, and 16.15, respectively.

The factors were named positive beliefs scale, negative beliefs scale, and permissive beliefs scale based on their content and previous research. Factor-loadings of the items on each of the three factors are presented in Table 4.

Table 3. Convergent and divergent validity

\begin{tabular}{|c|c|c|c|c|c|c|}
\hline Scale & EBQ & BES & DEBQ & $\mathrm{BICl}$ & IUS & AAQ \\
\hline EBQ & 1 & & & & & \\
\hline BES & $0.638^{* *}$ & 1 & & & & \\
\hline DEBQ & $0.627^{* *}$ & $0.630^{* *}$ & 1 & & & \\
\hline $\mathrm{BICl}$ & $-0.401^{* *}$ & $-0.594^{* *}$ & $-0.430^{* *}$ & 1 & & \\
\hline IUS & $-0.274^{* *}$ & $-0.346^{* *}$ & $-0.409^{* *}$ & 0.475 & 1 & \\
\hline AAQ-II & $-0.285^{* *}$ & $-0.316^{* *}$ & $-0.224^{* *}$ & 0.476 & $0.610^{* *}$ & 1 \\
\hline
\end{tabular}

EBQ: Eating Beliefs Questionnaire; BES: Binge Eating Scale; DEBQ: Dutch Eating Behavior Questionnaire; BICI: Body Image Concern Inventory; IUS: Intolerance of Uncertainty Scale; AAQ-II: Acceptance, and Action Questionnaire. ${ }^{* *} \mathrm{P}<0.01,{ }^{~} \mathrm{P}<0.05$ 
Table 4. Results of a confirmatory factor analysis of the Eating Beliefs Questionnaire (EBQ-18)

\begin{tabular}{|c|c|c|c|}
\hline EBQ-18 Items & F1: Negative Beliefs & F2: Positive Beliefs & F3: Permissive Beliefs \\
\hline I cannot control my urges to eat & 0.70 & & \\
\hline Once I start eating, I can't stop & 0.64 & & \\
\hline I have no willpower with food & 0.74 & & \\
\hline I can't control my eating because I am weak & 0.80 & & \\
\hline If I don't control myself, I will never stop eating & 0.72 & & \\
\hline There is nothing I can do to stop eating & 0.78 & & \\
\hline Eating means I don't have to think about negative things & & 0.81 & \\
\hline Eating helps to control my emotions & & 0.76 & \\
\hline Eating keeps my feelings at a tolerable level & & 0.84 & \\
\hline Eating helps me to cope with negative thoughts & & 0.90 & \\
\hline Eating helps me cope with negative feelings & & 0.87 & \\
\hline Eating is my best way of coping with unwanted feelings & & 0.71 & \\
\hline Bingeing is something that I can have for myself & & & 0.66 \\
\hline I deserve to have pleasure like binge eating & & & 0.77 \\
\hline It's okay to have the pleasant experience of binge eating & & & 0.82 \\
\hline It won't make a difference if I eat more & & & 0.50 \\
\hline I like to binge & & & 0.65 \\
\hline
\end{tabular}

F1=Factor 1, F2=Factor 2, F3=Factor 3

\section{Correlations between the EBQ-18 factors}

Table 5 presents correlation coefficients between the EBQ-18 factors. A moderate and positive correlation is demonstrated between the three factors: positive, negative, and permissive beliefs. The correlation between positive and negative beliefs is the highest, while the weakest correlation is observed between negative and permissive beliefs.

\section{Confirmatory Factor Analysis (CFA)}

To test the explored 3-factor structure further, secondorder CFA was used. The designed model assumes that each factor, which is identified by the related items, could represent a higher-order factor that is the cyberchondria. Figure 1 demonstrates the structural pattern of the 3-factor model: all the pathways are significant $(\mathrm{P}<0.001)$. For the model to show adequate fit, the value of the CFI, NFI, and the IFI should be higher than 0.9

Table 5. Correlations between the EBQ-18 factors

\begin{tabular}{cccc}
\hline Factors & Positive Beliefs & Negative Beliefs & Permissive Beliefs \\
\hline Positive Beliefs & 1 & & \\
Negative Beliefs & $0.582^{* *}$ & 1 & \\
Permissive Beliefs & $0.379^{* *}$ & $0.343^{* *}$ & 1 \\
\hline$* * P<0.01$ & & & PRACTICE In \\
\hline
\end{tabular}


Table 6. Confirmatory Factor Analysis (CFA)

\begin{tabular}{|c|c|c|c|c|c|c|}
\hline$x^{2}$ & df & $\chi^{2} / d f$ & RMSEA & NFI & CFI & IFI \\
\hline $607 / 40$ & 166 & 3.65 & 0.062 & 0.95 & 0.96 & 0.96 \\
\hline
\end{tabular}

$\chi^{2}$ : Chi-Square; $\mathrm{df}=$ degree of freedom; $\chi^{2} / \mathrm{df}$ : Chi-square ratio to the degree of freedom; RMSEA: Root Mean Square Error of Approximation; NFI: Normed Fit Index; CFI: Comparative of Fit Index; IFI: Incremental Fit Index

and the value of RMSEA and SRMR lower than 0.8 (ideally lower than 0.6 ). Besides, $\chi^{2} / \mathrm{df}$ should be less than 5 .

Table 6 presents the goodness-of-fit indices that validate the 3 -factor model showing adequate fit with the data. Evaluation of the standardized coefficients, as shown in the structural pattern (Figure 1), demonstrates that all factor loadings possess high values.

\section{Discussion}

Considering the prominent role of transdiagnostic approaches in cognitive-behavioral therapies, it seems necessary to provide a valid and reliable measure to assess transdiagnostic processes. Recently, transdiagnostic processes and components have been introduced: binge eating is of particular importance among these components (Burton et al., 2018; Burton et al., 2015; Burton et al., 2016) anorexia nervosa (binge/purge subtype. The current study aimed to examine the reliability and validity of the EBQ in a nonclinical Iranian sample. Firstly, the results of the psychometric properties of the EBQ18 were discussed, and then the results were interpreted. Results of the present study showed that the EBQ-18 possesses a 3-factor structure and a high internal consistency $(\alpha=0.91)$. Also, it is positively associated with the binge eating scale and the Dutch eating behavior questionnaire. It also demonstrated a moderate negative association with the body image concern inventory, the acceptance and action questionnaire-II, and the intolerance of uncertainty scale. These findings indicate that the EBQ-18 possesses appropriate psychometric properties and is a valid and reliable tool in the Iranian community. Thus, this measure demonstrates cross-cultural utility and executability within an Iranian sample.

Additionally, our findings are in line with the results of the previous research concerning the EBQ-32 in clinical and nonclinical populations (Burton et al., 2018; Burton et al., 2015; Burton et al., 2016) anorexia nervosa (binge/ purge subtype. The exploratory factor analysis using the varimax rotation method revealed three factors: posi-

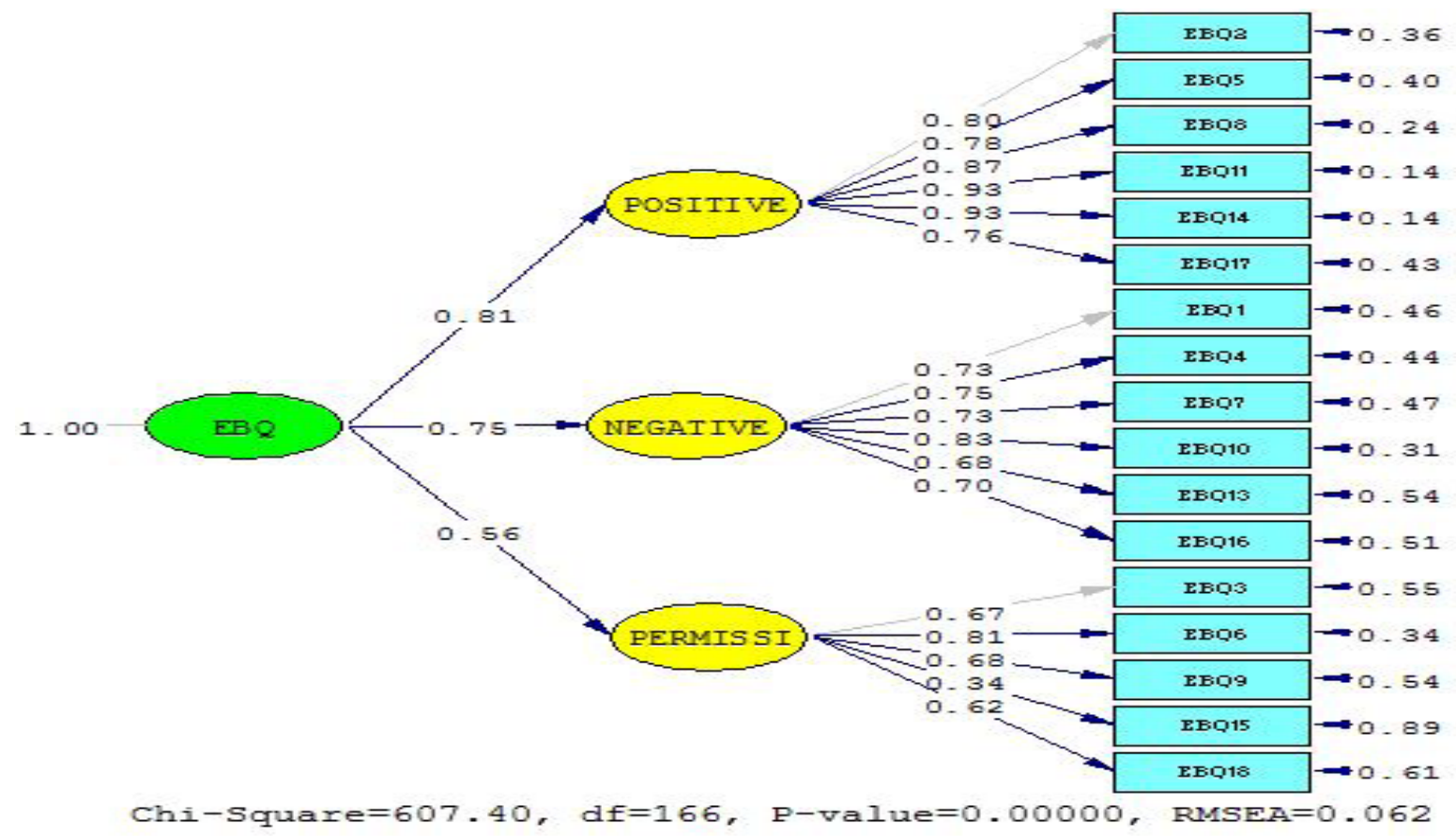

Figure 1. Factor structure of The Eating Beliefs Questionnaire (EBQ-18) 
tive, negative, and permissive beliefs about binge eating. The content of these three factors was also similar to the exact factors in the English version of the EBQ-18. In addition, the information obtained in this research is consistent with other similar studies (McCuen-Wurst et al., 2018; Burton et al., 2018; Arcelus, 2011). However, in most studies related to the symptoms of binge eating, only anorexia nervosa and bulimia nervosa have been emphasized, and the symptoms of binge eating have not been studied. However, binge eating is the most common component of eating disorders (Fairburn \& Harrison, 2003; Burton et al., 2015). According to the findings of the present research, participants who reported binge eating, or were suffering from the binge eating disorder as well as the bulimia nervosa, scored higher on the BEQ18 (McCuen-Wurst et al., 2018). These participants are probably more resistant to the therapeutic procedure that, in turn, leads to obesity, physical difficulties, further psychological disorders, and a reduction in the quality of life. Therefore, based on the literature, eating beliefs are related to binge eating and play a key role in eating disorders and emotional problems (McCuen-Wurst et al., 2018).

EBQ-18 identifies and evaluates beliefs related to binge eating and the severity of binge eating. By assessing this transdiagnostic construct in individuals who do not yet fulfill the diagnostic criteria of eating and emotional disorders, preventive measures could be taken to reduce the incidence of these disorders. Besides, due to the ease of implementation and the brevity of the EBQ18 , researchers and clinicians could utilize it to assess the effectiveness of psychological therapies.

Like other studies, the present research has some limitations that paying attention to them would pave the way for future research. Researching in nonclinical samples and few male participants limits the generalization of the results. Unfortunately, the level of cooperation of men in research is less than women. So to use this questionnaire for clinical and diagnostic purposes, it is suggested to study the validity and permanence of this scale in other groups of population (clinical and nonclinical population) and men.

\section{Conclusions}

Binge eating is a transdiagnostic structure that includes cognitive, emotional, and behavioral dimensions of the individual. The resulting physical and psychological problems increase economic, clinical, and social costs (Marzilli et al., 2018). So, providing a transdiagnostic model is necessary to reduce the symptoms of binge eating. So in this study, the psychometric properties (validity and reliability) of the Persian version of the short form of the EBQ (18-item version) were investigated in a nonclinical population. In conclusion, the EBQ-18 possesses proper psychometric properties in a nonclinical Iranian sample. Moreover, since this instrument measures one of the transdiagnostic constructs in the field of eating and emotional disorders, it can be used as a sensitive index to assess the effectiveness of transdiagnostic approaches in clinical trial studies. It is also beneficial for preventing other mental disorders and reducing economic and social costs (Marzilli et al., 2018).

\section{Ethical Considerations}

\section{Compliance with ethical guidelines}

All ethical principles were considered in this article. The participants were informed about the research objectives and its procedure. They were also assured about the confidentiality of their information. They were allowed to leave the study whenever they wished, and if desired, the research results would be available to them.

Ethical approval for this study was received from the Ethics Committee of Kharazmi University (IR.KHU. REC.1400.005) ("Iranian Academic Center for Education. Culture and Research: research ethic certificate" 2021).

\section{Funding}

This research did not receive any grant from funding agencies in the public, commercial, or non-profit sectors.

\section{Authors' contributions}

All authors equally contributed to preparing this article.

\section{Conflict of interest}

The authors declared no conflict of interest.

\section{References}

Abasi, E., Fatam, L., Moluodi, R., \& Zarabi, H. (2013). [Psychometric properties of Persian Version of acceptance and action questionnaire-II (Persian)]. Psychological Methods and Models, 3(10), 65-80. http://jpmm.miau.ac.ir/article_61.html

Akbari, M. (2017). [Psychometric properties of repetitive thinking questionnaire in nonclinical sample: Trans diagnostic tool (Persian)]. Journal of Clinical Psychology, 9(2), 59-70. [DOI:10.22075/JCP.2017.10345]

Akbari, M., \& Khanipour, H. (2018). The transdiagnostic model of worry: The mediating role of experiential avoidance. Personality and Individual Differences, 135, 166-72. [DOI:10.1016/j. paid.2018.07.011] 
Akbari, M., Roshan, R., Shabani, A., Fata, L., Shairi, M. R., \& Zarghami, F. (2015). [The comparison of the efficacy of transdiagnostic therapy based on repetitive negative thoughts with unified transdiagnostic therapy in treatment of patients with co-occurrence anxiety and depressive disorders: A randomized clinical trial (Persian)]. Iranian Journal of Psychiatry and Clinical Psychology, 21(2), 88-107. http://ijpcp.iums.ac.ir/ article-1-2416-en.html

American Psychiatric Association (APA). (2013). Diagnostic and statistical manual of mental disorders. Washington, DC: American Psychiatric Publishing. [DOI:10.1176/appi. books.9780890425596]

Arcelus, J. (2011). Mortality rates in patients with anorexia nervosa and other eating disorders. Archives of General Psychiatry, 68(7) 724-31. [DOI:10.1001/archgenpsychiatry.2011.74] [PMID]

Bond, F. W., Hayes, S. C., Baer, R. A., Carpenter, K. M., Guenole, N., \& Orcutt, H. K., et al. (2011). Preliminary psychometric properties of the acceptance and action questionnaire-II: A revised measure of psychological inflexibility and experiential avoidance. Behavior Therapy, 42(4), 676-88. [DOI:10.1016/j. beth.2011.03.007] [PMID]

Buhr, K., \& Dugas, M. (2002). The intolerance of uncertainty scale: Psychometric properties of the English version. Behav iour Research and Therapy, 40(8), 931-45. [DOI:10.1016/S00057967(01)00092-4]

Burton, A. L., Abbott, M. J., Modini, M., \& Touyz, S. (2016). Psychometric evaluation of self-report measures of binge-eating symptoms and related psychopathology: A systematic review of the literature. The International Journal of Eating Disorders, 49(2), 123-40. [DOI:10.1002/eat.22453] [PMID]

Burton, A. L., Hay, P., Smith, E., Raman, J., Swinbourne, J., \& Touyz, S., et al. (2015). Investigating the clinical utility of the Eating Beliefs Questionnaire: Validity, reliability and the results of a Confirmatory Factor Analysis. Journal of Eating Disorders, 3(Suppl 1), O51. [DOI:10.1186/2050-2974-3-S1-O51] [PMCID]

Burton, A. L., Mitchison, D., Hay, P., Donnelly, B., Thornton, C. \& Russell, J., et al. (2018). Beliefs about binge eating: Psychometric properties of the eating beliefs questionnaire (EBQ-18) in eating disorder, obese, and community samples. Nutrients, 10(9), 1306. [DOI:10.3390/nu10091306] [PMID] [PMCID]

Cockell, S. J., Geller, J., \& Linden, W. (2003). Decisional balance in anorexia nervosa: Capitalizing on ambivalence. European Eating Disorders Review, 11(2), 75-89. [DOI:10.1002/erv.493]

Cooper, Z., \& Grave, R. D. (2017). Eating disorders: Transdiagnostic Theory and Treatment. In S. G. Hofmann, \& G. J. G. Asmundson (Eds.), The Science of Cognitive Behavioral Therapy (pp. 337-57). Amsterdam: Elsevier Inc. [DOI:10.1016/B978-012-803457-6.00014-3]

Fairburn, C. G., Cooper, Z., Doll, H. A., O'Connor, M. E., Palmer, R. L., \& Dalle Grave, R. (2013). Enhanced cognitive behaviour therapy for adults with anorexia nervosa: A UK-Italy study. Behaviour Research and Therapy, 51(1), R2-8. [DOI:10.1016/j. brat.2012.09.010] [PMID] [PMCID]

Fairburn, C. G., \& Harrison, P. J. (2003). Eating disorders. The Lancet, 361(9355), 407-16. [DOI:10.1016/S0140-6736(03)12378-1] [PMID]

Fairburn, C. G., \& Harrison, P. J. (2003). Eating disorders. The Lancet, 361(9355), 407-16. [DOI:10.1016/S0140-6736(03)12378-1]

Goldschmidt, A. B., Wall, M. M., Loth, K. A., Bucchianeri, M. M., \& Neumark-Sztainer, D. (2014). The course of binge eat- ing from adolescence to young adulthood. Health Psychology, 33(5), 457-60. [DOI:10.1037/a0033508] [PMID] [PMCID]

Gormally, J., Black, S., Daston, S., \& Rardin, D. (1982). The assessment of binge eating severity among obese persons. Addictive Behaviors, 7(1), 47-55. [DOI:10.1016/0306-4603(82)90024-7]

Hayes, S. C., Strosahl, K. D., Wilson, K. G., Bissett, R. T., Pistorello, J., \& Toarmino, D., et al. (2004). Measuring experiential avoidance: A preliminary test of a working model. The Psychological Record, 54(4), 553-78. [DOI:10.1007/BF03395492]

Herzog, D. B., Sacks, N. R., Keller, M. B., Lavori, P. W., von Ranson, K. B., \& Gray, H. M. (1993). Patterns and predictors of recovery in anorexia nervosa and bulimia nervosa. Journal of the American Academy of Child \& Adolescent Psychiatry, 32(4), 835-42. [DOI:10.1097/00004583-199307000-00020] [PMID]

Jahnke, D. L., \& Warschburger, P. A. (2008). Familial transmission of eating behaviors in preschool-aged children. Obesity, 16(8), 1821-5. [DOI:10.1038/oby.2008.255] [PMID]

Kline, R. (2015). Principles and practice of structural equation modeling. New York: Guilford Publications. https:// books.google. com/books?id=Q61ECgAAQBAJ\&dq

Littleton, H. L., Axsom, D., \& Pury, C. L. S. (2005). Development of the body image concern inventory. Behaviour Research and Therapy, 43(2), 229-41. [DOI:10.1016/j.brat.2003.12.006] [PMID]

Marzilli, E., Cerniglia, L., \& Cimino, S. (2018). A narrative review of binge eating disorder in adolescence: Prevalence, impact, and psychological treatment strategies. Adolescent Health, Medicine and Therapeutics. 9, 17-30. [DOI:10.2147/AHMT. S148050] [PMID] [PMCID]

McCuen-Wurst, C., Ruggieri, M., \& Allison, K. C. (2018). Disordered eating and obesity: Associations between binge-eating disorder, night-eating syndrome, and weight-related comorbidities. Annals of the New York Academy of Sciences, 1411(1), 96-105. [DOI:10.1111/nyas.13467] [PMID] [PMCID]

Moloodi R, Dezhkam M., Moutabi F., \& Omidvar. N. (2010) [Comparison of early maladaptive schema in obese binge eaters and obese non-binge eaters (Persian)]. International Journal of Behavioral Sciences, 24(2), 109-14. https://www.sid.ir/fa/ journal/ViewPaper.aspx?ID=105226

Nattiv, A., Loucks, A. B., Manore, M. M., Sanborn, C. F., Sundgot-Borgen, J., 7 Warren, M. P., et al. (2007). American College of Sports Medicine position stand. The female athlete triad. Medicine and Science in Sports and Exercise, 39(10), 1867-82. [DOI:10.1249/mss.0b013e318149f111] [PMID]

Nobakht, M., \& Dezhkam, M. (2000). An epidemiological study of eating disorders in Iran. International Journal of Eating Disorders, 28(3), 265-71. [DOI:10.1002/1098108x(200011)28:3<265::aid-eat3>3.0.co;2-1] [PMID]

Pennesi, J.L., \& Wade, T. D. (2016). A systematic review of the existing models of disordered eating: Do they inform the development of effective interventions? Clinical Psychology Review, 43, 175-92. [DOI:10.1016/j.cpr.2015.12.004] [PMID]

Rezaei, M., Aflakseir, A., Yavari, A. A., \& Mohamadi N, \& Ghayour, M. (2015). [Designing and testing a model of thin internalization, self-objectification and body dissatisfaction as precedents of eating disorder risk in female university students (Persian)]. Iranian Journal of Nutrition Sciences $\mathcal{E}$ Food Technology, 10(2), 11-8. http://nsft.sbmu.ac.ir/article1-1646-en.htm 
Salehi Fadarid, J, Madaah Shoorcheh, R., \& Nemati, M. (2011) [A comparison of motivational structure and eating behaviors between overweight and obese and normal weight women (Persian)]. Journal of Fundamentals of Mental Health, 13(2), 17081. [DOI:10.22038/JFMH.2011.1017]

Stice, E., Marti, C. N., \& Rohde, P. (2013). Prevalence, incidence, impairment, and course of the proposed DSM-5 eating disorder diagnoses in an 8-year prospective community study of young women. Journal of Abnormal Psychology, 122(2), 445-57. [DOI:10.1037/a0030679] [PMID] [PMCID]

Tanofsky-Kraff, M., Shomaker, L. B., Olsen, C., Roza, C. A., Wolkoff, L. E., \& Columbo, K. M., et al. (2011). A prospective study of pediatric loss of control eating and psychological outcomes. Journal of Abnormal Psychology, 120(1), 108-18. [DOI:10.1037/a0021406] [PMID] [PMCID]

van Strien, T., Friiters, J. E. R., Bergers, G. P. A., \& Defares, P. B. (1986). The Dutch Eating Behavior Questionnaire (DEBQ) for assessment of restrained, emotional, and external eating behavior. International Journal of Eating Disorders, 5(2), 295-315. [DOI:10.1002/1098-108X(198602)5:2<295::AIDEAT2260050209>3.0.CO;2-T] 